\title{
Effects of methionine supplementation on the expression of oxidative stress-related genes in acute heat stress-exposed broilers
}

\author{
Ana Paula Del Vesco ${ }^{1}$, Eliane Gasparino ${ }^{1 *}$, Daiane de Oliveira Grieser ${ }^{1}$, Vittor Zancanela ${ }^{1}$, \\ Maria Amélia Menck Soares ${ }^{2}$ and Adhemar Rodrigues de Oliveira Neto ${ }^{3}$ \\ ${ }^{1}$ Department of Animal Science, Universidade Estadual de Maringá (UEM), Avenida Colombo, 5790 Maringá, \\ Paraná, Brazil \\ ${ }^{2}$ Department of Genetics, Universidade Federal Rural do Rio de Janeiro (UFRRJ), Seropédica, Rio de Janeiro, Brazil \\ ${ }^{3}$ Evonik-Degussa, Guarulhos, SP 07222-000, Brazil
}

(Submitted 8 July 2014 - Final revision received 24 September 2014 - Accepted 14 October 2014 - First published online 23 January 2015)

\section{Abstract}

The aim of the present study was to evaluate the effects of heat stress (HS) and methionine supplementation on the markers of stress and on the gene expression levels of uncoupling proteins (UCP), betaine-homocysteine methyltransferase (BHMT), cystathionine $\beta$-synthase $(C B S)$, glutathione synthetase (GSS) and glutathione peroxidase 7 (GPx7). Broilers from 1 to $21 \mathrm{~d}$ and from 22 to $42 \mathrm{~d}$ of age were divided into three treatment groups related to methionine supplementation: without methionine supplementation (MD); recommended level of methionine supplementation (DL1); excess methionine supplementation (DL2). The broilers were either kept at a comfortable thermal temperature or exposed to HS $\left(38^{\circ} \mathrm{C}\right.$ for $\left.24 \mathrm{~h}\right)$. During the starter period, we observed the effects of the interaction between diet and environment on the gene expression levels of $U C P, B H M T$ and GSS. Higher gene expression levels of $U C P$ and $B H M T$ were observed in broilers that were maintained at thermal comfort conditions and received the MD diet. HS broilers fed the DL1 and DL2 diets had the highest expression level of GSS. The expression levels of the CBS and GPx7 genes were influenced by both the environment and methionine supplementation. During the grower period, the gene expression levels of BHMT, CBS, GSS and GPx 7 were affected by the diet $\times$ environment interaction. A higher expression level of $B H M T$ was observed in broilers maintained at thermal comfort conditions and on the MD diet. HS induced higher expression levels of CBS, GSS and GPX7 in broilers that received the DL1 and DL2 diets. The present results suggest that under HS conditions, methionine supplementation could mitigate the effects of stress, since methionine contributed to the increased expression levels of genes related to antioxidant activity.

\section{Key words: Antioxidant system: Homocysteine: Methionine metabolism: Oxidative stress}

In the literature, oxidative stress has been the subject of several lines of research. Among these are the studies associated with diseases and metabolic disorders ${ }^{(1)}$, changes and damage to mitochondrial $\mathrm{DNA}^{(2)}$, effects of stress on autophagy ${ }^{(3)}$, on protein degradation $^{(4)}$ and on DNA methylation ${ }^{(5)}$, as well as the relationship between heat stress (HS) and oxidative stress ${ }^{(6-8)}$.

HS causes damage to the performance and the yield of parts of chickens, which may be explained by physiological changes to the bird's body ${ }^{(9,10)}$. These physiological changes might partly be due to oxidative stress that occurs in chickens exposed to HS. It is not entirely known how oxidative stress and HS are related; however, studies have shown that HS can induce mechanisms similar to those of oxidative stress such as increased lipid peroxidation ${ }^{(11)}$, decreased activity of the enzyme creatine kinase $(\mathrm{CK})^{(12)}$, and increased protein oxidation $^{(13)}$. HS is also associated with a decrease in the gene expression levels of uncoupling proteins $(U C P)^{(6,14)}$. $\mathrm{UCP}$ are proteins that are found in the inner mitochondrial membrane, and their main function in mammals is related to heat production ${ }^{(15)}$. This uncoupling mechanism in ATP production has also been described as an agent that enables a reduction in the production of reactive oxygen species (ROS) ${ }^{(16)}$. Thus, lower production of UCP can contribute to the induction of oxidative stress.

Large amounts of ROS are present when there is an oxidative stress state; this occurs not only due to the overproduction of ROS, but also due to the deficiency in the antioxidant defence system ${ }^{(17)}$. The antioxidant system of

Abbreviations: a.u., arbitrary units; ALT, alanine aminotransferase; AST, aspartate aminotransferase; BHMT, betaine-homocysteine methyltransferase; CBS, cystathionine $\beta$-synthase; CK, creatine kinase; DL1, recommended level of methionine supplementation; DL2, excess methionine supplementation; FI, feed intake; GPx, glutathione peroxidase; GSH, glutathione; GSS, glutathione synthetase; HS, heat stress; MD, without methionine supplementation; ROS, reactive oxygen species; UCP, uncoupling proteins; WG, weight gain.

*Corresponding author: E. Gasparino, fax +55 443011 4729, email egasparino@uem.br 
glutathione (GSH) is composed of the enzymes glutathione peroxidase (GPx) and GSH reductase; the effectiveness of the defence system depends on the coordinated activity of the whole ${ }^{(18)}$.

GSH biosynthesis occurs in most tissues based on three precursor amino acids. Among these is cysteine, which, during metabolism, can be synthesised from methionine by the transsulfuration pathway ${ }^{(19)}$. Methionine is involved in homocysteine metabolism via two metabolic pathways: remethylation, in which homocysteine is converted to methionine through the enzyme methionine synthase or betaine-homocysteine methyltransferase (BHMT); trans-sulfuration, in which homocysteine is converted to cysteine by the action of two enzymes, cystathionine $\beta$-synthase (CBS) and cystathionine $\beta$-lyase. It has been estimated that approximately $50 \%$ of GSH is generated from homocysteine, and that under conditions of oxidative stress, which requires higher amounts of GSH, the production rate increases through the stimulation of the trans-sulfuration pathway via the increased expression and activity of $C B S^{(20)}$. Results confirm that the presence of free radicals can induce the overexpression of $C B S$ and can also inhibit methionine synthase, thereby stimulating an increased production of cysteine and $\mathrm{GSH}^{(21)}$.

The present study was developed under the hypothesis that HS induces oxidative stress, and that methionine supplementation may contribute to the production and action of antioxidant components, thereby reducing the damage caused by stress. We assumed that remethylation is the main alternative pathway when there is a deficiency of methionine, and that trans-sulfuration mediated by $C B S$ is the main pathway when methionine is available for the synthesis of cellular components such as GSH. Thus, we aimed to evaluate the effects of HS and methionine supplementation on the markers of stress, on plasma homocysteine concentration, and on the expression levels of genes related to ROS production (UCP), genes involved in methionine metabolism (BHMT and $C B S$ ), and genes related to combating oxidative stress (glutathione synthetase (GSS) and GPx7) in broilers from 1 to $21 \mathrm{~d}$ and from 22 to $42 \mathrm{~d}$ of age.

\section{Materials and methods}

All procedures involving the birds used in the experiment were approved by the Committee on Animal Care of the Universidade Estadual de Maringá - Brazil.

\section{Experimental design and animals}

Expt 1: starter period (1-21d old). A total of 180 male broilers (Cobb 500, Gallus gallus) were used for the experiment conducted during the starter period. The broilers were divided into three treatment groups related to methionine supplementation: without methionine supplementation (MD, $n$ 60); recommended level of methionine supplementation (DL1, $n$ 60) ${ }^{(22)}$; excess methionine supplementation (DL2, $n$ 60) (Table 1). The broilers were distributed in a completely randomised design with four replications (pens) per treatment, and each replicate consisted of fifteen birds.
Throughout the experimental period, the broilers had free access to food and water.

The 180 birds distributed among the treatment groups were raised in a climatised room at thermal comfort conditions (according to Cobb guidelines) until $20 \mathrm{~d}$ of age, after which ninety birds (thirty from each treatment group) were exposed to acute $\mathrm{HS}$ of $38^{\circ} \mathrm{C}$ for $24 \mathrm{~h}$. During the stress period, the remaining ninety birds (thirty from each treatment group) were removed from the chamber and kept in a thermoneutral environment throughout the experiment. After $24 \mathrm{~h}$ of exposure to stress, the birds from both environments (thermal comfort and HS) were slaughtered by cervical dislocation at $21 \mathrm{~d}$. Before slaughtering, rectal temperature was measured in birds maintained at thermal comfort conditions and in those exposed to HS.

To calculate the weight gain (WG) of broilers kept at thermal comfort conditions, the birds were weighed at days 20 and 21 of the thermal comfort period. To calculate the WG of broilers exposed to HS, the birds were weighed at the beginning (day 20) and the end (day 21) of the stress period. Feed intake (FI) was calculated as the difference between the amount of feed offered at day 20 and the feed residue at the end of the trial (day 21) in both environments. FI and WG were corrected for mortality.

Expt 2: grower period (22-42d old). A total of 180 male broilers (Cobb 500, G. gallus) were used for the experiment conducted during the grower period. The birds were raised conventionally until $21 \mathrm{~d}$ of age, and fed a balanced diet to meet their nutritional demands ${ }^{(22)}$. After $21 \mathrm{~d}$, the birds were divided into three treatment groups related to methionine supplementation: MD ( $n$ 60); DL1 $(n 60)^{(22)}$; DL2 ( $n$ 60) (Table 1). The birds were distributed in a completely randomised design with four replications (pens) per treatment, and each replicate consisted of fifteen birds. Throughout the experimental period, the birds had free access to food and water.

The 180 birds distributed among the treatment groups were raised in a climatised room at thermal comfort conditions (according to Cobb guidelines) until $41 \mathrm{~d}$ of age, after which ninety birds (thirty from each treatment group) were exposed to acute $\mathrm{HS}$ of $38^{\circ} \mathrm{C}$ for $24 \mathrm{~h}$. During the stress period, the remaining ninety birds (thirty from each treatment group) were removed from the chamber and kept in a thermoneutral environment throughout the experiment. After $24 \mathrm{~h}$ of exposure to stress, the birds from both environments (thermal comfort and HS) were slaughtered by cervical dislocation at $42 \mathrm{~d}$. Before slaughtering, rectal temperature was measured in birds maintained at thermal comfort conditions and in those exposed to HS.

To calculate the WG of broilers maintained at thermal comfort conditions, the birds were weighed at days 41 and 42 of the thermal comfort period. To calculate the WG of broilers exposed to stress conditions, the birds were weighed at the beginning (day 41) and the end (day 42) of the stress period. FI was calculated as the difference between the amount of feed offered at day 41 and the feed residue at the end of the trial (day 42) in both environments. FI and WG were corrected for mortality. 
Table 1. Centesimal composition of the experimental diets (as-fed basis)

\begin{tabular}{|c|c|c|c|c|c|c|}
\hline & \multicolumn{3}{|c|}{ Starter period } & \multicolumn{3}{|c|}{ Grower period } \\
\hline & MD & DL1 & DL2 & MD & DL1 & DL2 \\
\hline \multicolumn{7}{|l|}{ Ingredients } \\
\hline Maize $(7.8 \% \mathrm{CP})$ & $550 \cdot 75$ & $548 \cdot 80$ & $542 \cdot 70$ & $600 \cdot 00$ & $598 \cdot 20$ & 592.05 \\
\hline Soyabean meal $(46.0 \% \mathrm{CP})$ & 373.00 & 373.00 & 374.00 & 324.00 & 324.00 & 325.00 \\
\hline Soya oil & 39.00 & 38.00 & $36 \cdot 00$ & $46 \cdot 00$ & 45.00 & 43.00 \\
\hline Salt & 4.50 & 4.50 & 4.50 & 4.30 & $4 \cdot 30$ & 4.30 \\
\hline Calcareous (38\%) & 11.60 & 11.60 & 11.60 & $9 \cdot 30$ & $9 \cdot 30$ & 9.25 \\
\hline Dicalcium phosphate (20\%) & $15 \cdot 25$ & $15 \cdot 25$ & $15 \cdot 30$ & $10 \cdot 65$ & $10 \cdot 70$ & $10 \cdot 70$ \\
\hline DL-Met $(99 \%)$ & - & 2.95 & $10 \cdot 00$ & - & $2 \cdot 75$ & $10 \cdot 00$ \\
\hline L-Lys HCl (78\%) & 1.55 & 1.55 & 1.55 & 1.55 & 1.55 & 1.50 \\
\hline L-Thr $(78 \%)$ & 0.35 & 0.35 & 0.35 & 0.20 & 0.20 & 0.20 \\
\hline Premix ${ }^{\star}$ & 4.00 & 4.00 & 4.00 & 4.00 & 4.00 & 4.00 \\
\hline Total & $1000 \cdot 00$ & $1000 \cdot 00$ & $1000 \cdot 00$ & $1000 \cdot 00$ & $1000 \cdot 00$ & $1000 \cdot 00$ \\
\hline \multicolumn{7}{|l|}{ Composition analysed (\%) } \\
\hline $\mathrm{CP}$ & $21 \cdot 61$ & $21 \cdot 77$ & $22 \cdot 191$ & $19 \cdot 73$ & 19.88 & $20 \cdot 36$ \\
\hline Lys (digestible) & $1 \cdot 19$ & $1 \cdot 19$ & 1.20 & 1.08 & 1.08 & 1.08 \\
\hline Met + Cys (digestible) & 0.58 & 0.88 & 1.57 & 0.54 & 0.81 & 1.53 \\
\hline Thr (digestible) & 0.78 & 0.78 & 0.78 & 0.70 & 0.70 & 0.70 \\
\hline Trp (digestible) & 0.24 & 0.24 & 0.24 & 0.22 & 0.22 & 0.22 \\
\hline Val (digestible) & 0.92 & 0.92 & 0.92 & 0.84 & 0.84 & 0.84 \\
\hline Ile (digestible) & 0.86 & 0.86 & 0.86 & 0.77 & 0.77 & 0.77 \\
\hline Arg (digestible) & $1 \cdot 38$ & $1 \cdot 38$ & 1.38 & 1.24 & $1 \cdot 24$ & 1.24 \\
\hline \multicolumn{7}{|l|}{ Composition calculated (\%)† } \\
\hline $\mathrm{Ca}$ & 0.88 & 0.88 & 0.88 & 0.68 & 0.68 & 0.68 \\
\hline $\mathrm{P}$ & 0.45 & 0.45 & 0.45 & 0.35 & 0.35 & 0.35 \\
\hline $\mathrm{Na}$ & 0.20 & 0.20 & 0.20 & 0.19 & 0.19 & 0.19 \\
\hline \multicolumn{7}{|l|}{ AME } \\
\hline $\mathrm{kJ} / \mathrm{kg}$ & $12771 \cdot 70$ & $12769 \cdot 31$ & 12766.97 & $13261 \cdot 61$ & $13257 \cdot 13$ & 13257.42 \\
\hline $\mathrm{kcal} / \mathrm{kg}$ & 3052.51 & 3051.94 & $3051 \cdot 38$ & $3169 \cdot 60$ & 3168.53 & $3168 \cdot 60$ \\
\hline
\end{tabular}

$M D$, without methionine supplementation; DL1, recommended level of methionine supplementation; DL2, excess methionine supplementation; $\mathrm{CP}$, crude protein; AME, apparent metabolisable energy.

* Supplied per kg of diet: retinyl acetate, $3.44 \mathrm{mg}$; cholecalciferol, $50 \mu \mathrm{g}$; DL- $\alpha$-tocopherol, $15 \mathrm{mg}$; thiamin, $1.63 \mathrm{mg}$; riboflavin, $4.9 \mathrm{mg}$; pyridoxine, $3.26 \mathrm{mg}$; cyanocobalamin, $12 \mu \mathrm{g}$; D-pantothenic acid, $9.8 \mathrm{mg}$; D-biotin, $0.1 \mathrm{mg}$; menadione, $2.4 \mathrm{mg}$; folic acid, $0.82 \mathrm{mg}$; niacinamide, $35 \mathrm{mg}$; Se, $0.2 \mathrm{mg} ; \mathrm{Fe}, 35 \mathrm{mg}$; Cu, $8 \mathrm{mg}$; Mn, $60 \mathrm{mg} ; \mathrm{Zn}, 50 \mathrm{mg}$; I, $1 \mathrm{mg}$; choline, $650 \mathrm{mg}$; salinomycin, $60 \mathrm{mg}$; avilamycin, $5 \mathrm{mg}$; butyl hydroxy toluene, $80 \mathrm{mg}$.

†Feed formulations were made based on the total amino acids of maize and soyabean meal as analysed by Evonik Degussa. The digestibility coefficient suggested by Rostagno et al. ${ }^{(22)}$ was used to calculate amino acid digestibility. Amino acids, CP and DM were analysed by Evonik Degussa.

\section{Plasma analyses}

After exposure to HS, the broilers were slaughtered and blood was collected from five birds per treatment (starter or grower period) for the analyses of homocysteine and uric acid contents, plasma CK, alanine aminotransferase (ALT) and aspartate aminotransferase (AST) activities. Blood was drawn from the jugular vein into heparin tubes and was kept on ice. After centrifugation $\left(3.024 \mathrm{~g}, 10 \mathrm{~min}, 4^{\circ} \mathrm{C}\right)$, plasma was collected and stored at $-20^{\circ} \mathrm{C}$ until further analysis.

Plasma homocysteine content was measured using the ADVIA Centaur (Siemens Healthcare Diagnostics) system by the method of chemiluminescence with a kit (09087913; Siemens Healthcare Diagnostics). Analyses of uric acid content, and ALT, AST and CK activities were carried out by colorimetric methods with the following kits, according to the manufacturer's recommendations (Gold Analisa): uric acid, MS 80022230171; ALT, MS 80022230086; AST, MS80022230083; total creatine kinase, MS 80022230088 . The enzyme activities of ALT and AST in the sample were calculated based on the rate of decrease in absorbance at $340 \mathrm{~nm}$ when $\mathrm{NADH}$ becomes $\mathrm{NAD}^{+}$. One unit of CK activity was defined as the amount of enzyme needed to convert $1 \mathrm{mmol}$ of creatine into creatine phosphate per min at $37^{\circ} \mathrm{C}, \mathrm{pH} 9 \cdot 0$.

\section{Gene expression}

For the analysis of gene expression, samples of breast muscle (Pectoralis superficialis) were collected from five broilers per treatment (starter or grower period), and stored in RNA Holders (BioAgency Biotecnologia) at $-20^{\circ} \mathrm{C}$ until total RNA extraction.

Total RNA was extracted using TRIzol ${ }^{\circledR}$ (Invitrogen) according to the manufacturer's instructions $(1 \mathrm{ml} / 100 \mathrm{mg}$ tissue). All the materials used were previously treated with the RNase inhibitor RNase AWAY ${ }^{\circledR}$ (Invitrogen). The tissue and TRIzol mixture was triturated with a Polytron electric homogeniser until complete dissociation was achieved. Then, $200 \mu \mathrm{l}$ chloroform was added to the sample, and the mixture was manually homogenised for $1 \mathrm{~min}$. The samples were then centrifuged for $15 \mathrm{~min}$ at $12000 \mathrm{rpm}$ and $4^{\circ} \mathrm{C}$. The aqueous phase was collected and transferred to a clean tube containing $500 \mu \mathrm{l}$ isopropanol, and was again homogenised and centrifuged for $15 \mathrm{~min}$ at $12000 \mathrm{rpm}$ and $4^{\circ} \mathrm{C}$. The supernatant was discarded, and the precipitate was washed with $1 \mathrm{ml}$ of $75 \%$ ethanol. The sample was again centrifuged at $12000 \mathrm{rpm}$ for $5 \mathrm{~min}$, and the supernatant was discarded. The pellet was dried for $15 \mathrm{~min}$ and resuspended in ultrapure RNase-free water. 
Table 2. Primer sequences used for quantitative real-time PCR

\begin{tabular}{lccl}
\hline Genes & Amplicon $(\mathrm{bp})$ & Annealing temperature $\left({ }^{\circ} \mathrm{C}\right)$ & Primer sequence $\left(5^{\prime}-3^{\prime}\right)$ \\
\hline UCP & 41 & 60 & GCAGCGGCAGATGAGCTT AGAGCTGCTTCACAGAGTCGTAGA \\
CBS & 146 & 60 & GAGTATGGAGAAGGTGGATGTC GGTCTAAGATATGTGCGTTGGG \\
BHMT & 96 & 60 & AGAGATTGTGATTGGAGATGGG TGTTCTACTGTTGCTTCGGG \\
GSS & 108 & 60 & GTGCCAGTTCCAGTTTTCTTATG TCCCACAGTAAAGCCAAGAG \\
GPX7 & 140 & 60 & TTGTAAACATCAGGGGCAAA TGGGCCAAGATCTTTCTGTAA \\
$\beta$-Actin & 136 & 60 & ACCCCAAAGCCAACAGA CCAGAGTCCATCACAATACC \\
\hline
\end{tabular}

$U C P$, uncoupling proteins; $C B S$, cystathionine $\beta$-synthase; BHMT, betaine-homocysteine methyltransferase; GSS, glutathione synthetase; GPX7, glutathione peroxidase 7 .

Total RNA concentration was measured using a spectrophotometer at a wavelength of $260 \mathrm{~nm}$. RNA integrity was analysed using a $1 \%$ agarose gel stained with $10 \%$ ethidium bromide and visualised under UV light. The RNA samples were treated with DNase I (Invitrogen), according to the manufacturer's instructions, in order to remove possible genomic DNA contamination.

Complementary DNA was synthesised using a SuperScript ${ }^{\mathrm{TM}}$ III First-Strand Synthesis Super Mix (Invitrogen) kit, according to the manufacturer's instructions. For this reaction, $6 \mu \mathrm{l}$ of total RNA, $1 \mu \mathrm{l}$ of oligo dT $\left(50 \mu \mathrm{m}\right.$-oligo $\left.(\mathrm{dT})_{20}\right)$ and $1 \mu \mathrm{l}$ of annealing buffer were added to a sterile RNA-free tube. The reaction was then incubated for $5 \mathrm{~min}$ at $65^{\circ} \mathrm{C}$ and placed on ice for $1 \mathrm{~min}$. Subsequently, $10 \mu \mathrm{l}$ of $2 \times$ First-Strand Reaction Mix and $2 \mu \mathrm{l}$ of solution containing the SuperScript III Reverse Transcriptase enzyme and RNase inhibitor were added to the tubes. The solution was incubated for $50 \mathrm{~min}$ at $50^{\circ} \mathrm{C}$ for the synthesis of complementary DNA. Then, the reaction was incubated for $5 \mathrm{~min}$ at $85^{\circ} \mathrm{C}$ and was immediately placed on ice. The samples were stored at $-20^{\circ} \mathrm{C}$ until further use.

Real-time PCR were performed using the fluorescent dye SYBR Green $\left(\mathrm{SYBR}^{\circledR}\right.$ Green PCR Master Mix; Applied Biosystems). All the reactions were analysed under the same conditions and normalised to the ROX reference dye (Invitrogen) in order to correct for fluctuations in the readings due to evaporation during the reaction.

The primers used in the amplification reactions of UCP, BHMT, CBS, GPX7 and GSS were designed based on gene sequences deposited at http://www.ncbi.nlm.nih.gov (accession no. AF433170.2, XM_414685.3, XM_416752.3, NM_001163245.1 and XM_425692.3, respectively) using the website http://www.idtdna.com (Table 2). For normalisation of mRNA expression, two endogenous controls, $\beta$-actin and glyceraldehyde-3-phosphate dehydrogenase (GAPDH), were tested, and $\beta$-actin (accession no. L08165) was selected because its amplification was shown to be more efficient. All analyses were performed in duplicate, each in a volume of $25 \mu \mathrm{l}$.

\section{Statistical analysis}

Statistical analysis was performed separately for each experimental period. The $2^{-\Delta C_{\mathrm{T}}}$ method was used to analyse the changes in the relative expression of genes. Data for WG during the grower period (22-42 d of age) were analysed using the GENMOD procedure. Means were compared by contrasts. Data from other variables were analysed using the general linear model procedure, and means were compared by Tukey's test $(P<0.05)$ (SAS Institute, Inc.). Results are expressed as means and standard deviations.

\section{Results}

\section{Performance}

Regardless of the experimental period (1-21 or $22-42 \mathrm{~d}$ of age), we observed that acute $\mathrm{HS}\left(38^{\circ} \mathrm{C}\right.$ for $\left.24 \mathrm{~h}\right)$ was sufficient to increase the body temperature of broilers: $40 \cdot 21 \pm 0 \cdot 30^{\circ} \mathrm{C}$ (thermal comfort) $v \cdot 41.99 \pm 0.12^{\circ} \mathrm{C}$ (HS) $(P<0 \cdot 0001)$ for birds in the starter period; $41.51 \pm 0.33 v .42 .87 \pm 0.21^{\circ} \mathrm{C}$ $(P<0 \cdot 0001)$ for birds in the grower period.

The WG, FI and mortality of birds in the starter and grower periods are shown in Table 3. HS broilers in the starter period exhibited lower weight gain $(P=0.0018)$ and lower FI ( $P=0.0016$ ); regarding methionine supplementation, the broilers that received the DL1 diet had higher WG than those fed the MD diet $(P=0 \cdot 0169)$.

In the grower period, the broilers kept at thermal comfort conditions exhibited higher WG $(P<0.0001)$ and higher FI $(P<0 \cdot 0001)$ than those exposed to HS. Regarding methionine supplementation, the lowest FI was observed in broilers fed the DL2 diet. The effect of methionine supplementation on the WG of broilers was also observed. The differences between the means can be calculated through contrasts. The broilers fed the MD diet had lower WG than those fed the DL1 $(P=0.0499)$ and DL2 $(P=0.0182)$ diets. No difference in WG was observed between the DL1 and DL2 diets $(P=0.6172)$.

In the starter and grower periods, a higher mortality rate in broilers exposed to HS and fed the MD diet was also observed.

\section{Gene expression}

Table 4 presents the gene expression of birds recorded in the starter period for the three diets and two environments studied.

Gene expression levels of UCP $(P=0.0095), \quad B H M T$ $(P<0.0001)$ and GSS $(P=0.0012)$ in the muscle of broilers were influenced by the interaction between temperature and diet. The broilers maintained at thermal comfort conditions and fed the MD diet exhibited higher gene expression levels of $\operatorname{UCP}$ (3.25 arbitrary units (a.u.)) and BHMT (0.67 a.u.). Similarly, the broilers exposed to HS and fed the DL1 and DL2 diets exhibited a higher expression level of GSS. 
Table 3. Weight gain (WG) and feed intake (FI) of broilers in the starter and grower periods

(Mean values and standard deviations)

\begin{tabular}{|c|c|c|c|c|c|c|c|c|c|c|c|c|c|}
\hline & & \multicolumn{6}{|c|}{ Starter period } & \multicolumn{6}{|c|}{ Grower period } \\
\hline & & \multicolumn{2}{|c|}{ WG (kg) } & \multicolumn{2}{|c|}{$\mathrm{FI}(\mathrm{kg})$} & \multicolumn{2}{|c|}{ Mortality (\%) } & \multicolumn{2}{|c|}{ WG (kg) } & \multicolumn{2}{|c|}{$\mathrm{FI}(\mathrm{kg})$} & \multicolumn{2}{|c|}{ Mortality (\%) } \\
\hline & & Mean & SD & Mean & SD & Mean & SD & Mean & SD & Mean & SD & Mean & $\mathrm{SD}$ \\
\hline \multirow[t]{3}{*}{ Comfort } & MD & 0.040 & 0.003 & 0.070 & 0.006 & $1 \cdot 20^{c}$ & 0.07 & 0.084 & 0.004 & 0.154 & 0.007 & $1 \cdot 38^{c}$ & 0.13 \\
\hline & DL1 & 0.046 & 0.002 & 0.066 & 0.001 & $1 \cdot 16^{c}$ & 0.05 & 0.090 & 0.005 & 0.141 & 0.005 & $1 \cdot 21^{\mathrm{c}}$ & 0.07 \\
\hline & DL2 & 0.044 & 0.002 & 0.064 & 0.004 & $1 \cdot 11^{c}$ & 0.02 & 0.085 & 0.011 & 0.139 & 0.009 & $1 \cdot 18^{\mathrm{c}}$ & 0.04 \\
\hline \multirow[t]{3}{*}{ Stress } & MD & 0.016 & 0.006 & 0.061 & 0.001 & $2 \cdot 60^{\mathrm{a}}$ & 0.22 & -0.339 & 0.262 & 0.074 & 0.012 & $5 \cdot 63^{a}$ & 0.16 \\
\hline & DL1 & 0.034 & 0.011 & 0.063 & 0.003 & $1.94^{b}$ & 0.11 & -0.155 & 0.048 & 0.067 & 0.011 & $3.68^{b}$ & 0.36 \\
\hline & DL2 & 0.026 & 0.013 & 0.059 & 0.003 & $1 \cdot 91^{b}$ & 0.04 & -0.103 & 0.029 & 0.060 & 0.006 & $3.78^{b}$ & 0.10 \\
\hline \multicolumn{14}{|l|}{ Main effects } \\
\hline \multirow[t]{2}{*}{ Environment } & Comfort & $0.044^{a}$ & 0.003 & $0.066^{a}$ & 0.004 & $1 \cdot 16$ & 0.06 & 0.087 & 0.027 & $0.141^{a}$ & 0.012 & $1 \cdot 26$ & 0.12 \\
\hline & Stress & $0.025^{b}$ & 0.011 & $0.060^{b}$ & 0.003 & $2 \cdot 15$ & 0.36 & -0.199 & 0.027 & $0.067^{b}$ & 0.011 & 4.35 & 0.97 \\
\hline \multirow[t]{3}{*}{ Diet } & MD & $0.030^{\mathrm{b}}$ & 0.014 & 0.066 & 0.007 & 1.90 & 0.76 & -0.127 & 0.033 & $0.137^{a}$ & 0.044 & 3.51 & $2 \cdot 28$ \\
\hline & DL1 & $0.041^{\mathrm{a}}$ & 0.010 & 0.065 & 0.002 & 1.55 & 0.43 & -0.032 & 0.033 & $0 \cdot 104^{a}$ & 0.041 & 2.44 & 1.34 \\
\hline & DL2 & $0.036^{a, b}$ & 0.010 & 0.062 & 0.004 & $1 \cdot 51$ & 0.43 & -0.009 & 0.033 & $0.094^{b}$ & 0.037 & $2 \cdot 47$ & $1 \cdot 38$ \\
\hline \multicolumn{14}{|l|}{ Probabilities } \\
\hline Environment & & \multicolumn{2}{|c|}{$<0.0001$} & \multicolumn{2}{|c|}{0.0025} & \multicolumn{2}{|c|}{$<0.0001$} & \multicolumn{2}{|c|}{$<0.0001$} & \multicolumn{2}{|c|}{$<0.0001$} & \multicolumn{2}{|c|}{$<0.0001$} \\
\hline Diet & & \multicolumn{2}{|c|}{0.0260} & \multicolumn{2}{|c|}{ NS } & \multicolumn{2}{|c|}{$<0.0001$} & \multicolumn{2}{|c|}{0.0457} & \multicolumn{2}{|c|}{0.0016} & \multicolumn{2}{|c|}{$<0.0001$} \\
\hline Interaction & & \multicolumn{2}{|c|}{ NS } & \multicolumn{2}{|c|}{ NS } & \multicolumn{2}{|c|}{$<0.0001$} & \multicolumn{2}{|c|}{ NS } & $\Lambda$ & & $<0$ & 001 \\
\hline Contrast $\left(P>\chi^{2}\right)$ & & & & & & & & & & & & & \\
\hline $\mathrm{MD}-\mathrm{DL} 1$ & & & & & & $0 \cdot($ & 499 & & & & & & \\
\hline MD - DL2 & & & & & & $0 \cdot($ & 182 & & & & & & \\
\hline DL1 - DL2 & & & & & & & 172 & & & & & & \\
\hline Comfort - heat stress & & & & & & $<0$ & 001 & & & & & & \\
\hline
\end{tabular}

MD, without methionine supplementation; DL1, recommended level of methionine supplementation; DL2, excess methionine supplementation.

${ }^{a, b, c}$ Mean values within a row with unlike superscript letters were significantly different $(P<0.05)$.

The gene expression levels of $C B S$ and $G P x 7$ were influenced by both methionine supplementation $(P=0.0167$ and 0.0042 , respectively) and HS $(P<0.0001$ and 0.0004 , respectively). The gene expression levels of $C B S$ and GPX7 were higher in broilers that received the DL1 and DL2 diets in comparison to those fed the MD diet, and also in broilers exposed to HS in comparison to those maintained at thermal comfort conditions.

Table 4. Gene expression levels of uncoupling proteins (UCP), betaine-homocysteine methyltransferase (BHMT), cystathionine $\beta$-synthase (CBS), glutathione synthetase (GSS) and glutathione peroxidase 7 (GPX7) in the muscle of broilers in the starter period (Mean values and standard deviations)

\begin{tabular}{|c|c|c|c|c|c|c|c|c|c|c|c|}
\hline & & \multicolumn{2}{|c|}{ UCP (a.u.) } & \multicolumn{2}{|c|}{ BHMT (a.u.) } & \multicolumn{2}{|c|}{ CBS (a.u.) } & \multicolumn{2}{|c|}{ GSS (a.u.) } & \multicolumn{2}{|c|}{ GPx7 (a.u.) } \\
\hline & & Mean & SD & Mean & SD & Mean & SD & Mean & SD & Mean & SD \\
\hline \multirow[t]{3}{*}{ Comfort } & $M D$ & $3 \cdot 25^{\mathrm{a}}$ & 1.40 & $0.67^{\mathrm{a}}$ & 0.21 & 0.74 & 0.23 & $0.99^{b}$ & 0.13 & 1.08 & 0.37 \\
\hline & DL1 & $1.56^{\mathrm{b}}$ & 0.83 & $0 \cdot 11^{\mathrm{b}}$ & 0.04 & $2 \cdot 30$ & 0.68 & $1 \cdot 15^{\mathrm{a}, \mathrm{b}}$ & 0.31 & $1 \cdot 80$ & 0.19 \\
\hline & DL2 & $1.51^{b}$ & 0.76 & $0 \cdot 10^{\mathrm{b}}$ & 0.04 & 2.08 & 1.21 & $0.94^{b, c}$ & 0.23 & 1.56 & 0.27 \\
\hline \multirow[t]{3}{*}{ Stress } & MD & $1 \cdot 29^{b}$ & 0.48 & $0 \cdot 10^{\mathrm{b}}$ & 0.05 & $2 \cdot 73$ & 1.51 & $0.54^{c}$ & 0.15 & $1 \cdot 70$ & 0.70 \\
\hline & DL1 & $1.50^{\mathrm{b}}$ & 0.57 & $0.09^{b}$ & 0.02 & 3.28 & 0.48 & $1.58^{a, b}$ & 0.37 & $2 \cdot 46$ & 0.57 \\
\hline & DL2 & $1 \cdot 49^{\mathrm{b}}$ & 0.48 & $0.08^{b}$ & 0.03 & 3.31 & 0.83 & $1 \cdot 79^{\mathrm{a}}$ & 0.22 & $2 \cdot 45$ & 0.50 \\
\hline \multicolumn{12}{|l|}{ Main effects } \\
\hline \multirow[t]{2}{*}{ Environment } & Comfort & $2 \cdot 11$ & 1.28 & 0.29 & 0.03 & $1.70^{\mathrm{b}}$ & 0.90 & 1.03 & 0.24 & $1.48^{b}$ & 0.44 \\
\hline & Stress & 1.43 & 0.49 & 0.09 & 0.01 & $3.11^{\mathrm{a}}$ & 1.01 & 1.30 & 0.43 & $2 \cdot 20^{\mathrm{a}}$ & 0.74 \\
\hline \multirow[t]{3}{*}{ Diet } & $\mathrm{MD}$ & $2 \cdot 28$ & 1.44 & 0.39 & 0.03 & $1 \cdot 74^{\mathrm{b}}$ & 0.46 & 0.76 & 0.19 & $1.39^{b}$ & 0.46 \\
\hline & DL1 & 1.53 & 0.68 & 0.10 & 0.04 & $2 \cdot 79^{a}$ & 0.76 & 1.36 & 0.48 & $2 \cdot 13^{\mathrm{a}}$ & 0.53 \\
\hline & DL2 & 1.50 & 0.61 & 0.09 & 0.01 & $2 \cdot 70^{\mathrm{a}}$ & 1.18 & $1 \cdot 37$ & 0.49 & $2 \cdot 00^{a}$ & 0.60 \\
\hline \multicolumn{12}{|l|}{ Probabilities } \\
\hline \multicolumn{2}{|l|}{ Environment } & \multicolumn{2}{|c|}{0.0196} & \multicolumn{2}{|c|}{$<0.0001$} & \multicolumn{2}{|c|}{$<0.0001$} & \multicolumn{2}{|c|}{0.0438} & \multicolumn{2}{|c|}{0.0004} \\
\hline Diet & & \multirow{2}{*}{\multicolumn{2}{|c|}{$\begin{array}{l}0.0464 \\
0.0095\end{array}$}} & \multirow{2}{*}{\multicolumn{2}{|c|}{$<0.0001$}} & \multirow{2}{*}{\multicolumn{2}{|c|}{$\begin{array}{l}0.0167 \\
\text { NS }\end{array}$}} & \multirow{2}{*}{\multicolumn{2}{|c|}{0.0007}} & \multicolumn{2}{|c|}{0.0042} \\
\hline \multicolumn{2}{|l|}{ Interaction } & & & & & & & & 0.0012 & \multicolumn{2}{|c|}{ NS } \\
\hline
\end{tabular}

a.u., Arbitrary units; MD, without methionine supplementation; DL1, recommended level of methionine supplementation; DL2, excess methionine supplementation.

a,b,c Mean values within a row with unlike superscript letters were significantly different $(P<0.05)$. 
Table 5. Gene expression levels of uncoupling proteins (UCP), betaine-homocysteine methyltransferase (BHMT), cystathionine $\beta$-synthase (CBS), glutathione synthetase (GSS) and glutathione peroxidase 7 (GPX7) in the muscle of broilers in the grower period (Mean values and standard deviations)

\begin{tabular}{|c|c|c|c|c|c|c|c|c|c|c|c|}
\hline & & \multicolumn{2}{|c|}{ UCP (a.u.) } & \multicolumn{2}{|c|}{ BHMT (a.u.) } & \multicolumn{2}{|c|}{ CBS (a.u.) } & \multicolumn{2}{|c|}{ GSS (a.u.) } & \multicolumn{2}{|c|}{ GPX7 (a.u.) } \\
\hline & & Mean & SD & Mean & SD & Mean & SD & Mean & SD & Mean & SD \\
\hline \multirow[t]{3}{*}{ Comfort } & $M D$ & 0.78 & 0.33 & $0 \cdot 16^{\mathrm{a}}$ & 0.05 & $0.79^{c}$ & 0.25 & $0.70^{\mathrm{b}}$ & 0.30 & $1 \cdot 20^{\mathrm{C}}$ & 0.46 \\
\hline & DL1 & 0.37 & 0.19 & $0.03^{b}$ & 0.01 & $2 \cdot 45^{\mathrm{b}}$ & 0.72 & $1.24^{\mathrm{b}}$ & 0.45 & $1.95^{\mathrm{C}}$ & 0.20 \\
\hline & DL2 & 0.36 & 0.18 & $0.02^{b}$ & 0.02 & $1 \cdot 78^{\mathrm{b}, \mathrm{c}}$ & 0.59 & $1 \cdot 22^{b}$ & 0.32 & $1.54^{\mathrm{C}}$ & 0.36 \\
\hline \multirow[t]{3}{*}{ Stress } & MD & 0.31 & 0.11 & $0.01^{b}$ & 0.01 & $1 \cdot 80^{\mathrm{b}, \mathrm{c}}$ & 0.56 & $0.97^{b}$ & 0.19 & $3 \cdot 79^{\mathrm{b}}$ & 1.53 \\
\hline & DL1 & 0.25 & 0.12 & $0.02^{\mathrm{b}}$ & 0.01 & $6 \cdot 57^{\mathrm{a}}$ & 0.96 & $2 \cdot 75^{\mathrm{a}}$ & 1.20 & $5 \cdot 03^{a}$ & $1 \cdot 17$ \\
\hline & DL2 & 0.25 & 0.09 & $0.01^{\mathrm{b}}$ & 0.01 & $7 \cdot 12^{\mathrm{a}}$ & 1.52 & $3.25^{\mathrm{a}}$ & 0.52 & $6 \cdot 02^{a}$ & 0.76 \\
\hline \multicolumn{12}{|l|}{ Main effects } \\
\hline \multirow{2}{*}{ Environment } & Comfort & $0.50^{\mathrm{a}}$ & 0.30 & 0.07 & 0.01 & 1.67 & 0.87 & 1.05 & 0.42 & 1.57 & 0.46 \\
\hline & Stress & $0.27^{\mathrm{b}}$ & 0.10 & 0.02 & 0.01 & $5 \cdot 16$ & 2.66 & $2 \cdot 33$ & 1.23 & 4.95 & 1.46 \\
\hline \multirow[t]{3}{*}{ Diet } & MD & $0.54^{\mathrm{a}}$ & 0.34 & 0.09 & 0.01 & $1 \cdot 29$ & 0.67 & 0.84 & 0.27 & $2 \cdot 49$ & 1.73 \\
\hline & DL1 & $0.31^{\mathrm{b}}$ & 0.16 & 0.03 & 0.01 & 4.50 & $2 \cdot 30$ & 1.99 & $1 \cdot 17$ & 3.49 & 1.79 \\
\hline & DL2 & $0.30^{\mathrm{b}}$ & 0.14 & 0.02 & 0.02 & 4.45 & 1.00 & $2 \cdot 23$ & 1.03 & 3.79 & 1.41 \\
\hline \multicolumn{12}{|l|}{ Probabilities } \\
\hline \multirow{2}{*}{\multicolumn{2}{|c|}{$\begin{array}{l}\text { Environment } \\
\text { Diet }\end{array}$}} & \multirow{2}{*}{\multicolumn{2}{|c|}{$\begin{array}{l}0.0010 \\
0.0063\end{array}$}} & \multirow{2}{*}{\multicolumn{2}{|c|}{$<0.0001$}} & \multicolumn{2}{|c|}{$<0.0001$} & \multicolumn{2}{|c|}{$<0.0001$} & \multicolumn{2}{|c|}{$<0.0001$} \\
\hline & Diet & & & & & \multirow{2}{*}{\multicolumn{2}{|c|}{$<0.0001$}} & \multirow{2}{*}{\multicolumn{2}{|c|}{$\begin{array}{r}<0.00036 \\
0.0031\end{array}$}} & \multirow{2}{*}{\multicolumn{2}{|c|}{$\begin{array}{l}0.0032 \\
0.0375\end{array}$}} \\
\hline Interaction & & \multicolumn{2}{|c|}{ NS } & \multicolumn{2}{|c|}{$<0.0001$} & & & & & & \\
\hline
\end{tabular}

a.u., Arbitrary units; MD, without methionine supplementation; DL1, recommended level of methionine supplementation; DL2, excess methionine supplementation.

a,b,c Mean values within a row with unlike superscript letters were significantly different $(P<0.05)$.

Similar to the starter period, there was an interaction effect on almost all of the gene expression levels in the grower period. The gene expression levels of BHMT $(P<0 \cdot 0001)$, CBS $(P<0 \cdot 0001)$, GSS $(P=0 \cdot 0036)$ and GPx7 were influenced by the interaction between temperature and methionine supplementation (Table 5).

The expression level of BHMT was higher in broilers kept at thermal comfort conditions and fed the MD diet (0.16a.u.). No difference in the expression level of BHMT was observed among the other treatments.

HS broilers fed the DL1 and DL2 diets exhibited an increase in the gene expression level of CBS (6.57 and 7.12a.u., respectively). The lowest expression level was observed in broilers maintained at thermal comfort conditions and fed the MD diet (0.79a.u.).

A higher expression level of GSS was observed in HS broilers fed the DL1 and DL2 diets. However, no difference was observed among the other treatments.

The highest gene expression level of GPx 7 was found in HS broilers fed the higher amounts of methionine (DL1 and DL2). The broilers exposed to HS and fed the MD diet exhibited a higher expression level of GPx 7 than those kept at thermal comfort conditions. No difference was observed among the three treatments in broilers kept at thermal comfort conditions.

No interaction effect on the expression level of $U C P$ was observed between diet and temperature. However, the expression level was influenced by both variables. A decreased expression level of $U C P$ was observed in HS broilers in comparison to those kept at thermal comfort conditions $(0 \cdot 27 v$. 0.50 a.u.; $P=0.0010$ ). Regarding methionine supplementation, the broilers fed the DL1 and DL2 diets exhibited a lower expression level of $U C P$ than those fed the MD $\operatorname{diet}(P=0 \cdot 0063)$.

\section{Plasma analyses}

Homocysteine content was also influenced by the interaction between environment and methionine supplementation $(P=0.0022)$. The highest homocysteine level was observed in broilers fed the DL2 diet and kept at thermal comfort conditions, and the lowest level was found in HS broilers fed the MD and DL1 diets (Fig. 1).

The effects of methionine supplementation and HS on plasma CK, AST and ALT activities in the starter period are presented in Table 6.

An interaction effect between the factors on the activities of uric acid $(P<0.0001)$ and ALT $(P=0.0024)$ was observed. The highest level of uric acid was found in broilers maintained at thermal comfort conditions and fed the DL1

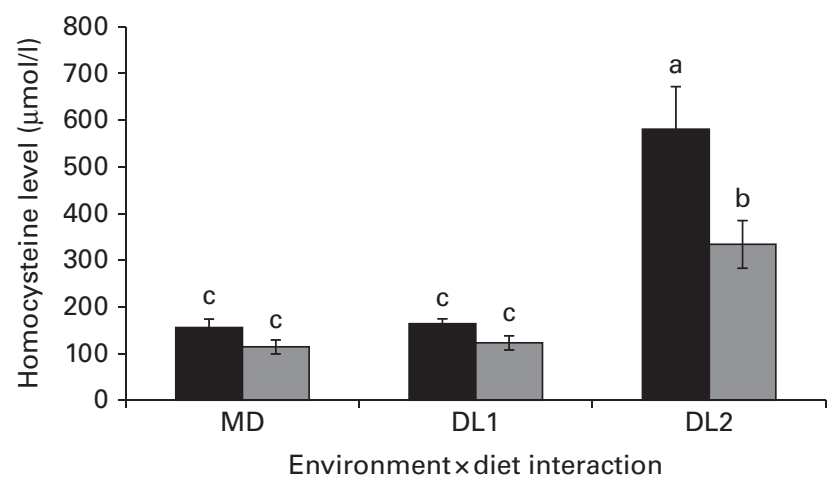

Fig. 1. Effects of the interaction between methionine supplementation and environment on plasma homocysteine level in broilers during the starter period. Values are means, with their standard deviations represented by vertical bars. ${ }^{a, b, c}$ Mean values with unlike letters were significantly different $(P<0.05)$. MD, without methionine supplementation; DL1, recommended level of methionine supplementation; DL2, excess methionine supplementation. $\square$, Comfort; $\mathbf{\square}$, stress. 
Table 6. Plasma analyses of uric acid, creatine kinase (CK), aspartate aminotransferase (AST), and alanine aminotransferase (ALT) activities in broilers during the starter period

(Mean values and standard deviations)

\begin{tabular}{|c|c|c|c|c|c|c|c|c|c|}
\hline & & \multicolumn{2}{|c|}{$\begin{array}{l}\text { Uric acid } \\
(\mu \mathrm{mol} / \mathrm{l})\end{array}$} & \multicolumn{2}{|c|}{ CK (units/l) } & \multicolumn{2}{|c|}{ AST (units/l) } & \multicolumn{2}{|c|}{ ALT (units/l) } \\
\hline & & Mean & SD & Mean & SD & Mean & SD & Mean & SD \\
\hline \multirow[t]{3}{*}{ Comfort } & $M D$ & $385^{\mathrm{b}}$ & 102 & 543.03 & 96.56 & 295.83 & $36 \cdot 13$ & $4.83^{\mathrm{c}}$ & 0.98 \\
\hline & DL1 & $652^{\mathrm{a}}$ & 98 & 697.63 & 137.45 & 298.50 & 83.61 & $4.67^{c}$ & 0.81 \\
\hline & DL2 & $302^{b}$ & 61 & 460.07 & 58.93 & $245 \cdot 67$ & 24.64 & $4.67^{c}$ & 1.37 \\
\hline \multirow[t]{3}{*}{ Stress } & MD & $103^{\mathrm{c}}$ & 36 & 323.80 & 113.54 & 292.50 & $50 \cdot 88$ & $24.67^{a}$ & 6.02 \\
\hline & DL1 & $96^{c}$ & 71 & 281.97 & $109 \cdot 02$ & $260 \cdot 67$ & $16 \cdot 68$ & $16 \cdot 50^{\mathrm{b}}$ & 7.42 \\
\hline & DL2 & $121^{c}$ & 27 & 257.68 & $103 \cdot 36$ & $228 \cdot 40$ & 35.00 & $12 \cdot 17^{b}$ & 0.41 \\
\hline \multicolumn{10}{|l|}{ Main effects } \\
\hline \multirow[t]{2}{*}{ Environment } & Comfort & 446 & 175 & $567.5^{\mathrm{a}}$ & 265.09 & 280.00 & $56 \cdot 96$ & 4.72 & 1.01 \\
\hline & Stress & 106 & 47 & $287 \cdot 8^{\mathrm{b}}$ & 105.92 & $262 \cdot 41$ & 43.64 & $17 \cdot 78$ & 7.44 \\
\hline \multirow[t]{3}{*}{ Diet } & MD & 244 & 164 & 434.41 & $153 \cdot 12$ & $294 \cdot 17^{a}$ & $42 \cdot 11$ & $14 \cdot 75$ & 4.98 \\
\hline & DL1 & 374 & 64 & 489.80 & 173.51 & $279 \cdot 58^{a, b}$ & $60 \cdot 79$ & $10 \cdot 58$ & $2 \cdot 75$ \\
\hline & DL2 & 211 & 104 & 358.87 & $132 \cdot 68$ & $237 \cdot 82^{b}$ & $29 \cdot 58$ & $8 \cdot 41$ & 1.90 \\
\hline \multicolumn{10}{|l|}{ Probabilities } \\
\hline \multicolumn{2}{|l|}{ Environment } & \multicolumn{2}{|c|}{$<0.0001$} & \multicolumn{2}{|c|}{0.0002} & \multicolumn{2}{|c|}{ NS } & \multicolumn{2}{|c|}{$<0.0001$} \\
\hline Diet & & \multicolumn{2}{|c|}{$<0.0001$} & \multicolumn{2}{|c|}{ NS } & \multicolumn{2}{|c|}{0.0190} & \multicolumn{2}{|c|}{0.0018} \\
\hline Interaction & & \multicolumn{2}{|c|}{$<0.0001$} & \multicolumn{2}{|c|}{ NS } & \multicolumn{2}{|c|}{ NS } & \multicolumn{2}{|c|}{0.0024} \\
\hline
\end{tabular}

$\mathrm{MD}$, without methionine supplementation; DL1, recommended level of methionine supplementation; DL2, excess methionine supplementation.

a,b,c Mean values within a row with unlike superscript letters were significantly different $(P<0.05)$.

$\operatorname{diet}(652 \mu \mathrm{mol} / \mathrm{l} ; 10.97 \mathrm{mg} / \mathrm{dl})$, and the lowest level was found in those exposed to HS, regardless of the diet. The highest level of ALT was observed in broilers exposed to HS and fed the MD diet (24.67 units/1).

An environmental effect on CK activity $(P=0.0002)$ was observed, with lower activity being found in HS broilers. Meanwhile, methionine supplementation had an effect on AST activity $(P=0 \cdot 0190)$, with the highest activity being observed in broilers fed the MD diet, and the lowest activity in those fed the DL2 diet.

The effects of methionine supplementation and HS on plasma CK, AST and ALT activities in the grower period are presented in Table 7.

Plasma CK $(P<0.0001)$ and ALT $(P=0.0004)$ activities were influenced by the interaction between temperature and diet. CK activity was found to be higher in broilers maintained at thermal comfort conditions and fed the DL1 diet (1908.00 units/1). The highest ALT activity was observed in HS broilers fed the MD diet (10.00 units/1), and the lowest activity in those maintained at thermal comfort conditions and fed the DL2 diet (5.17 units/1).

Uric acid content was influenced by both temperature and diet. An increased level of uric acid was observed in broilers kept at thermal comfort conditions (259 v. $190 \mu \mathrm{mol} / 14.36 v$. $3.20 \mathrm{mg} / \mathrm{dl} ; \quad P=0.0002)$. Regarding the diet, the level of uric acid increased in those fed the DL1 diet $(P=0 \cdot 0017)$.

The treatments did not influence the activity of AST in broilers from 22 to $42 \mathrm{~d}$ of age.

\section{Discussion}

Broiler, layer and breeder production are quite affected by high temperatures found in some tropical countries during the summer season. These high temperatures cause damage to the performance and the yield of parts of chickens, which can be explained by the physiological changes that occur in the bird's body ${ }^{(9,10)}$. When birds are exposed to HS, environmental and postural mechanisms such as reduction in FI and increase in water intake are used primarily in an attempt to reduce metabolic heat production and increase heat dissipation $^{(23)}$. In broilers exposed to HS environment at $42 \mathrm{~d}$ of age, a huge decrease in weight was observed, even though the period of evaluation was only $24 \mathrm{~h}$. Although the observed reduction cannot be explained completely, research in the literature has shown that broilers exposed to high temperatures increase their plasma corticosterone levels, which stimulates a huge increase in the breakdown of proteins in the bird's body ${ }^{(10)}$.

In the present study, it was observed that acute $\mathrm{HS}\left(38^{\circ} \mathrm{C}\right.$ for $24 \mathrm{~h}$ ) increased the body temperature of even the birds in the starter period (1-21 d old). The higher body temperature observed in HS broilers can induce metabolic changes such as increased ROS production and increased lipid peroxidation; thus, increased body temperature can contribute to HS-induced oxidative stress ${ }^{(24)}$. ROS are produced mainly as a function of proton leakage during phosphorylative oxidation; however, the mechanism of ROS production in HS birds is not yet fully known ${ }^{(25)}$. The effects of HS are possibly due to an accelerated rate of ROS formation or an increase in ROS reactivity ${ }^{(26)}$.

The production of ROS in broilers exposed to high temperatures has also been correlated with the potential of the mitochondrial membrane and the expression of the UCP gene ${ }^{(27)}$. A greater mitochondrial membrane potential is associated with higher ROS production, and higher UCP mRNA production is associated with a lower production of 
Table 7. Plasma analyses of uric acid, creatine kinase (CK), aspartate aminotransferase (AST) and alanine aminotransferase (ALT) activities in broilers during the grower period

(Mean values and standard deviations)

\begin{tabular}{|c|c|c|c|c|c|c|c|c|c|}
\hline & & \multicolumn{2}{|c|}{$\begin{array}{l}\text { Uric acid } \\
(\mu \mathrm{mol} / \mathrm{l})\end{array}$} & \multicolumn{2}{|c|}{ CK (units/l) } & \multicolumn{2}{|c|}{ AST (units/l) } & \multicolumn{2}{|c|}{ ALT (units/l) } \\
\hline & & Mean & SD & Mean & SD & Mean & SD & Mean & SD \\
\hline \multirow[t]{3}{*}{ Comfort } & MD & 233 & 53 & $1608 \cdot 83^{b}$ & $119 \cdot 3$ & 299.00 & $179 \cdot 60$ & $5 \cdot 67^{\mathrm{b}, \mathrm{c}}$ & 0.52 \\
\hline & DL1 & 324 & 8 & $1908 \cdot 00^{\mathrm{a}}$ & $214 \cdot 6$ & 397.33 & 27.49 & $9 \cdot 67^{\mathrm{a}}$ & $4 \cdot 22$ \\
\hline & DL2 & 220 & 9 & $1602 \cdot 30^{b}$ & $262 \cdot 0$ & $340 \cdot 17$ & $106 \cdot 44$ & $5 \cdot 17^{c}$ & 0.41 \\
\hline \multirow[t]{3}{*}{ Stress } & MD & 156 & 30 & $1120 \cdot 80^{c}$ & 180.8 & $409 \cdot 83$ & 34.00 & $10 \cdot 00^{\mathrm{a}}$ & 0.00 \\
\hline & DL1 & 214 & 79 & $1520 \cdot 62^{b}$ & $118 \cdot 4$ & 447.00 & 23.85 & $7 \cdot 33^{b}$ & 1.03 \\
\hline & DL2 & 202 & 60 & $388.57^{d}$ & 144.5 & $331 \cdot 17$ & 89.93 & $5 \cdot 33^{b, c}$ & 0.52 \\
\hline \multicolumn{10}{|l|}{ Main effects } \\
\hline \multirow[t]{2}{*}{ Environment } & Comfort & $259^{a}$ & 54 & $1706 \cdot 37$ & 243.8 & $345 \cdot 50$ & 121.07 & 6.83 & $3 \cdot 11$ \\
\hline & Stress & $190^{\mathrm{b}}$ & 62 & 1009.99 & 502.5 & 389.63 & 74.85 & 7.55 & 2.06 \\
\hline \multirow[t]{3}{*}{ Diet } & $\mathrm{MD}$ & $194^{\mathrm{b}}$ & 58 & $1364 \cdot 72$ & $122 \cdot 3$ & 354.42 & 135.55 & $7 \cdot 83$ & $2 \cdot 28$ \\
\hline & DL1 & $269^{a}$ & 79 & 1714.40 & 452.5 & $417 \cdot 20$ & 35.59 & 8.50 & $3 \cdot 17$ \\
\hline & DL2 & $211^{b}$ & 42 & 995.43 & $265 \cdot 2$ & 335.67 & 94.06 & $5 \cdot 25$ & 0.45 \\
\hline \multicolumn{10}{|l|}{ Probabilities } \\
\hline \multicolumn{2}{|l|}{ Environment } & \multicolumn{2}{|c|}{0.0002} & \multicolumn{2}{|c|}{$<0.0001$} & \multicolumn{2}{|c|}{ NS } & \multicolumn{2}{|c|}{ NS } \\
\hline Diet & & \multicolumn{2}{|c|}{0.0017} & \multicolumn{2}{|c|}{$<0.0001$} & \multicolumn{2}{|c|}{ NS } & \multicolumn{2}{|c|}{0.0003} \\
\hline Interaction & & \multicolumn{2}{|c|}{ NS } & \multicolumn{2}{|c|}{$<0.0001$} & \multicolumn{2}{|c|}{ NS } & \multicolumn{2}{|c|}{0.0004} \\
\hline
\end{tabular}

free radicals, resulting in less cellular damage due to decreased ROS content. A greater mitochondrial membrane potential and decreased UCP mRNA expression has been observed in broilers exposed to $\mathrm{HS}^{(7)}$.

UCP can reduce ROS production by affecting decoupling during the production of $\mathrm{ATP}^{(16)}$; therefore, maintaining the appropriate levels of UCP mRNA transcripts could help to combat the overproduction of ROS and oxidative stress that is caused by acute HS. The expression of $U C P$ is influenced by environmental factors such as $\mathrm{HS}^{(6)}$ and nutritional status $^{(28)}$. As found in the literature ${ }^{(6,14)}$, we also observed lower expression levels of $U C P$ in broilers exposed to HS in the present study. Regarding methionine supplementation, we observed that broilers fed the MD diet exhibited higher expression levels of $U C P$. This result is consistent with that reported previously that broilers fed a MD diet exhibit a worse feed conversion ratio or feed efficiency ${ }^{(29)}$. Despite the beneficial effect of UCP in reducing the damage to DNA and cell proteins, as it reduces the production of free radicals, a higher mRNA expression of UCP may worsen the feed conversion ratio, as it reduces the production of $\operatorname{ATP}^{(30,31)}$.

The organism's defence against ROS may be mediated by non-enzymatic and enzymatic antioxidants that are mainly represented by superoxide dismutase and catalase enzymes and by the GSH defence system ${ }^{(32)}$. GSH is involved in a variety of biological actions, including protection against toxic compounds and mainly defence against free radicals ${ }^{\text {(33) }}$. In the organism, GSH can be biosynthesised by three amino acids: glutamic acid; glycine; cysteine. Cysteine, in turn, can be synthesised in the body via the methionine metabolic pathway, which is composed of methylation, remethylation and trans-sulfuration. In the remethylation pathway, homocysteine is converted to methionine by the action of two enzymes: methionine synthase and BHMT. Trans-sulfuration occurs in two stages: in the first stage, homocysteine reacts with serine by the action of CBS, resulting in the synthesis of cystathionine; in the second stage, cystathionine is metabolised by cystathionine $\beta$-lyase, resulting in the synthesis of cysteine ${ }^{(34)}$.

The synthesis of GSH also occurs in two steps. In the first step, a link between the amino acids cysteine and glutamic acid occurs by the action of the $\gamma$-glutamylcysteine synthetase enzyme. This reaction results in the synthesis of $\gamma$-L-glutamylL-cysteine. In the second phase, the dipeptide is linked to glycine by $\mathrm{GSS}^{(18)}$.

It has been estimated that approximately $50 \%$ of $\mathrm{GSH}$ is generated from homocysteine, and that under oxidative stress conditions, the production rate increases through the stimulation of the trans-sulfuration pathway via the increased expression and activity of CBS and the inhibition of methionine synthase, which are the enzymes responsible for the synthesis of cysteine and methionine, respectively ${ }^{(20,21)}$.

In the present study, we evaluated the gene expression levels of CBS, BHMT, GSS and GPX7, and found that acute HS and higher methionine content increased the expression levels of CBS, GSS and GPx7. These results suggest that birds exposed to HS attempt to avoid increased ROS production by increasing the expression levels of genes that are part of or that contribute to the antioxidant system of GSH. Because adequate levels of methionine are required for greater efficiency of the antioxidant system, better results were observed in broilers fed the DL1 and DL2 diets.

We found that the gene expression of BHMT was lower in HS broilers. Since remethylation was inhibited, the amount of BHMT mRNA was found to be lower even when the HS birds were fed the MD diet, thereby indicating that the 
organism under stress can stimulate the production of $\mathrm{GSH}$ even when fed diets that are poor in methionine. In contrast, we observed a higher gene expression level of BHMT in broilers kept at thermal comfort conditions and fed the MD diet. This result was expected because during normal metabolism, remethylation is favoured when there is a low methionine or $S$-adenosylmethionine concentration ${ }^{(34,35)}$.

Homocysteine is an endogenous amino acid formed as an intermediate product of methionine metabolism. In the body, most of the homocysteine is linked to proteins, and most of the portion that is in the free form is either oxidised and forms dimers (homocysteine) or combines with cysteine $^{(36)}$. A high concentration of homocysteine in the blood is known as hyperhomocysteinaemia and is associated with several diseases. When the normal metabolism of transsulfuration and remethylation is disturbed, usually by CBS deficiency, cysteine levels are decreased and there is lower antioxidant capacity; meanwhile, methionine levels may increase dramatically, which may cause a disease known as homocystinuria type $\mathrm{I}^{(37)}$.

Because of the importance of homocysteine in methionine metabolism and its involvement in the synthesis and action of enzymes that were used in the experiments of the present study, we evaluated plasma homocysteine concentration in broilers between 1 and $21 \mathrm{~d}$ of age. We observed that, in general, HS broilers showed a lower homocysteine concentration. The highest concentration of homocysteine was observed in broilers that were maintained at thermal comfort conditions and fed the DL2 diet. The broilers fed the DL2 diet and exposed to HS exhibited higher homocysteine concentrations than those fed the MD and DL1 diets, regardless of the environment. These results are consistent with the other results of the present study. A lower homocysteine concentration in HS broilers was expected because higher amounts of cysteine are produced from homocysteine through the increased action of the CBS enzyme. In addition, higher homocysteine concentrations observed in broilers fed the DL2 diet correspond to our hypothesis because with higher methionine levels in the diet, requirements of this amino acid are more easily met; therefore, a lower gene expression level of BHMT was observed, resulting in increased plasma homocysteine concentration.

Uric acid, similar to so many other metabolites, has been reported in the literature as one of many elements that exhibit antioxidant activity. At the physiological $\mathrm{pH}$ range, it is commonly found in the form of urate, a powerful ROS scavenger released into the bloodstream by deleterious reactions such as $\mathrm{Hb}$ auto-oxidation or peroxide production by macrophages. Urate can inactivate an oxidant before they can react with biological molecules such as DNA, proteins and lipid membranes ${ }^{(38)}$.

Birds possess specific mechanisms that contribute to increased urate concentrations in the blood, such as the absence of the enzyme uricase and the ability to encapsulate uric acid with proteins. Studies have indicated a relationship between higher uric acid concentrations and the decreased presence of oxidative stress markers ${ }^{(39,40)}$.

In the present study, we observed lower uric acid content in broilers exposed to HS than in those kept at thermal comfort conditions. This result indicates that under stress conditions, a higher concentration of uric acid was used to combat ROS production, by decreasing their concentration in these broilers. The broilers fed the methionine-supplemented diets had higher uric acid concentration. This suggests that stress demands an increased concentration of this antioxidant in the plasma, and that this increased level results from methionine supplementation because the presence of this amino acid can increase FI and concomitantly glycine intake, which is a necessary element for the synthesis of uric acid. Methionine supplementation ${ }^{(41)}$ and increased FI have been linked to increased plasma uric acid concentration levels in broiler chickens ${ }^{(42)}$.

The activity of the enzyme CK can be considered as a certain kind of oxidative stress marker, since previous studies in the literature link oxidative stress to decreased $\mathrm{CK}$ activity $^{(43,44)}$, possibly via the oxidation of the thiol group. The activity of the enzyme can be preserved by endogenous GSH, which serves as a protective agent during the half-life of the enzyme in the circulation; the loss of activity under certain conditions cannot be recovered when the extracellular GSH concentration is decreased, even in the presence of thiolreducing agents ${ }^{(45)}$. In the present study, we observed that broilers exposed to HS demonstrated lower activity of this enzyme; and we also observed that in stress conditions, broilers fed the DL1 diet demonstrated greater activity than those fed the MD diet. This result may be due to a protective role of GSH in CK activity.

Similar to CK activity, the activities of AST and ALT enzymes in the plasma have been consistently associated with stress. This is due to the fact that these enzymes are released into the blood when the body suffers some kind of injury ${ }^{(46)}$ However, unlike CK, increased activity of AST and ALT has been observed in animals under stress ${ }^{(47-49)}$. In the present study, increased activity of these enzymes was observed in HS broilers fed the MD diet. A deficiency in methionine, as we have observed, may have contributed to the decreased action of GSH system components, and thus resulting in greater damage to the birds.

These results allow us to suggest that under HS conditions in which the body temperature was greatest, methionine supplementation could mitigate the effects of stress, since the supplementation contributed to the increased expression of genes related to cysteine and GSH production as well as to the increased expression of the GPx7 gene. The broilers exposed to stress and fed the methionine-supplemented diets showed better results in the activities of enzymes used as stress markers, which could be due to higher antioxidant capacity.

\section{Acknowledgements}

The present study was supported by the Brazilian National Council for Research - CNPq (E. G., grant no. 483751/ 2012-0). CNPq had no role in the design or analysis of the study or in the writing of this article.

The authors' contributions are as follows: A. P. D. V., E. G. and A. R. d. O. N. were responsible for the conception and design of the study; A. P. D. V., E. G. and M. A. M. S carried 
out the gene expression analysis; A. P. D. V., V. Z. and D. d. O. G. conducted the experiment, contributed to the data collection, and carried out the plasma analysis; E. G. performed the statistical analysis; A. P. D. V. and E. G. were responsible for the data interpretation. All authors contributed and approved the final version of the manuscript.

None of the authors has any conflict of interest to declare.

\section{References}

1. Moustafa MH, Sharma RK, Thornton J, et al. (2004) Relationship between ROS production, apoptosis and DNA denaturation in spermatozoa from patients examined for infertility. Human Reprod 19, 129-138.

2. Lee HC \& Wei YH (2005) Mitochondrial biogenesis and mitochondrial DNA maintenance of mammalian cells under oxidative stress. Int J Biochem Cell Biol 37, 822-834.

3. Lee J, Giordano S \& Zhang J (2012) Autophagy, mitochondria and oxidative stress: cross-talk and redox signalling. Biochem J 441, 523-540.

4. Aiken CT, Kaake RM, Wang X, et al. (2011) Oxidative stressmediated regulation of proteasome complexes. Mol Cell Proteomics 10, R110.006924.

5. Gu X, Sun J, Li S, et al. (2013) Oxidative stress induces DNA demethylation and histone acetylation in SH-SY5Y cells: potential epigenetic mechanisms in gene transcription in A $\beta$ production. Neurobiol Aging 34, 1069-1079.

6. Mujahid A, Sato K, Akiba Y, et al. (2006) Acute heat stress stimulates mitochondrial superoxide production in broiler skeletal muscle, possibly via downregulation of uncoupling protein content. Poult Sci 85, 1259-1265.

7. Mujahid A, Akiba Y \& Toyomizu M (2009) Olive oilsupplemented diet alleviates acute heat stress-induced mitochondrial ROS production in chicken skeletal muscle. Am J Physiol Regul Integr Comp Physiol 297, R690-R698.

8. Yang L, Tan GY, Fu QF, et al. (2010) Effects of acute heat stress and subsequent stress removal on function of hepatic mitochondrial respiration, ROS production and lipid peroxidation in broiler chickens. Comp Biochem Physiol C Toxicol Pharmacol 151, 204-208.

9. Geraert PA, Padilha JCF \& Guillaumin S (1996) Metabolic and endocrine changes induced by chronic heat exposure chickens: biological and endocrinological variables. $\mathrm{Br} J$ Nutr 75, 205-216.

10. Yunianto V, Hayashi K, Kaneda S, et al. (1997) Effect of environmental temperature on muscle protein turnover and heat production in tube-fed broiler chicken. Br J Nutr 77, 897-909.

11. Willemsen H, Swennen Q, Everaert N, et al. (2011) Effects of dietary supplementation of methionine and its hydroxy analog DL-2-hydroxy-4-methylthiobutanoic acid on growth performance, plasma hormone levels, and the redox status of broiler chickens expose to high temperatures. Poult $S c i$ 90, 2311-2320.

12. Del Vesco AP, Gasparino E, Grieser DO, et al. (2014) Effects of methionine supplementation on the redox state of acute heat stress-exposed quails. J Anim Sci 92, 806-815.

13. Ronsein GE, Miyamoto S, Bechara E, et al. (2006) Oxidação de proteínas por oxigênio singlete: mecanismos de dano, estratégias para detecção e implicações biológicas (Protein oxidation by singlet oxygen: damage mechanisms, strategies for detection and biological implications). Quimica Nova 29, 563-568.

14. Gasparino E, Voltolini DM, Del Vesco AP, et al. (2013) IGF-I, GHR and $U C P$ mRNA expression in the liver and muscle of high- and low-feed-efficiency laying Japanese quail at different environmental temperatures. Livest Sci 157, 339-344.

15. Ledesma A, Lacoba MG \& Rial E (2000) The mitochondrial uncoupling proteins. Genome Biol 3, 3015.1-3015.9.

16. Abe T, Mujahid A, Sato K, et al. (2006) Possible role of avian uncoupling protein in down-regulating mitochondrial superoxide production in skeletal muscle of fasted chickens. FEBS Lett 580, 4815-4822.

17. Halliwell B \& Gutteridge JMC (2001) Free Radicals in Biology and Medicine, 3rd ed. New York: Oxford University Press.

18. Huber PC, Almeida WP \& Fátima A (2008) Glutationa e enzimas relacionadas: Papel biológico e importância em processos patológicos (Glutathione and related enzymes: biological role and importance in pathological processes). Química Nova 31, 1170-1179.

19. Shoveller AK, Stoll B, Ball RO, et al. (2005) Nutritional and functional importance of intestinal sulfur amino acid metabolism. J Nutr 135, 1609-1612.

20. Mosharov E, Cranford MR \& Banerjee R (2000) The quantitatively important relationship between homocysteine metabolism and glutathione synthesis by the transsulfuration pathway and its regulation by redox changes. Biochemistry 39, 13005-13011.

21. Persa C, Pierce A, Ma Z, et al. (2004) The presence of a transsulfuration pathway in the lens: a new oxidative stress defense system. Exp Eye Res 79, 875-886.

22. Rostagno HS, Albino LFT, Donzele JL, et al. (2011) Brazilian Tables for Birds and Pigs: Composition of Foods and Nutritional Requirements, 3rd ed. Viçosa: Universidade Federal de Viçosa.

23. Mujahid A, Yoshiki Y, Akiba Y, et al. (2005) Super-oxide radical production in chicken skeletal muscle induced by acute heat stress. Poult Sci 84, 307-314.

24. Lin H, Decuypere E \& Buyse J (2006) Acute heat stress induces oxidative stress in broiler chickens. Comp Biochem Physiol Mol Integr Physiol 144, 11-17.

25. Tan GY, Yang L, Fu QF, et al. (2010) Effects of different acute high ambient temperatures on function of hepatic mitochondrial respiration, antioxidative enzymes, and oxidative injury in broiler chickens. Poult Sci 89, 115-122.

26. Bai Z, Harvey LM \& McNeil B (2003) Elevated temperature effects on the oxidant/antioxidant balance in submerged batch cultures of the filamentous fungus Aspergillus niger B1. Biotechnol Bioeng 83, 772-779.

27. Fink BD, Rezka KJ, Herlein JA, et al. (2005) Respiratory uncoupling by UCP1 and UCP2 and superoxide generation in endothelial cell mitochondria. Am J Physiol Endocrinol Metab 288, E71-E79.

28. Evock-Clover CM, Poch SM, Richards MP, et al. (2002) Expression of an uncoupling protein gene homologue in chickens. Comp Biochem Physiol A Mol Integr Physiol 133, 345-358.

29. Del Vesco AP, Gasparino E, Oliveira Neto AR, et al. (2013) Effect of methionine supplementation on mitochondrial genes expression in the breast muscle and liver of broilers. Livest Sci 151, 284-291.

30. Ojano-Dirain C, Toyomizu M, Wing T, et al. (2007) Gene expression in breast muscle and duodenum from low and high feed efficient broilers. Poult Sci 86, 372-381.

31. Raimbault S, Dridi S, Denjean F, et al. (2001) An uncoupling protein homologue putatively involved in facultative thermogenesis in birds. Biochem J 353, 441-444.

32. Kuss F (2005) Agentes oxidantes e antioxidants (Oxidizing agents and antioxidants). In Seminário apresentado na disciplina bioquímica do tecido animal, no Programa de Pós-Graduação em Ciências Veterinárias da Universidade 
Federal do Rio Grande do Sul em 2005 (Seminar Presented at the Discipline of Animal Tissue Biochemistry in the Graduate Program in Veterinary Sciences, Federal University of Rio Grande do Sul, 2005). Porto Alegre: Federal University of Rio Grande do Sul. http://www6.ufrgs.br/ favet/lacvet/restrito/pdf/ag_oxid_antioxid.pdf

33. Morand C, Rios L, Moundras C, et al. (1997) Influence of methionine availability on glutathione synthesis and delivery by the liver. J Nutr Biochem 8, 246-255.

34. Stipanuk MH (2004) Sulfur amino acid metabolism: pathways for production and removal of homocysteine and cysteine. Annu Rev Nutr 24, 539-577.

35. Finkelstein JD (1998) The metabolism of homocysteine: pathways and regulation. Eur J Pediatr 157, S40-S44.

36. Dietrich-Muszalska A, Malinowska J, Olas B, et al. (2012) The oxidative stress may be induced by the elevated homocysteine in schizophrenic patients. Neurochem Res 37, 1057-1062.

37. Ramakrishnan S, Sulochana KN, Lakshmi S, et al. (2006) Biochemistry of homocysteine in health and diseases. Indian J Biochem Biophys 43, 275-283.

38. Sautin YY \& Johnson RJ (2008) Uric acid: the oxidantantioxidant paradox. Nucleosides Nucleotides Nucleic Acids 27, 608-619.

39. Klandorf H, Rathore D, Iqbal M, et al. (2001) Accelerated tissue aging and increased oxidative stress in broiler chickens fed allopurinol. Comp Biochem Physiol C Toxicol Pharmacol 129, 93-104.

40. Simoyi M, Van Dyke K \& Klandorf H (2002) Manipulation of plasma uric acid broiler chicks and its effect on leukocyte oxidative activity. Am J Physiol Regul Integr Comp Physiol 282, R791-R796.

41. Bunchasak C, Sooksridang T \& Chaiyapit R (2006) Effect of adding methionine hydroxy analogue as methionine source at the commercial requirement recommendation on production performance and evidence of ascites syndrome of male broiler chicks fed corn-soybean based. Int J Poult Sci 5, 744-752.

42. Machin M, Simoyi MF, Blemings KP, et al. (2004) Increased dietary protein elevates plasma uric acid and is associated with decreased oxidative stress in rapidly-growing broilers. Comp Biochem Physiol B Biochem Mol Biol 137, 383-390.

43. Glaser V, Leipnitz G, Straliotto MR, et al. (2010) Oxidative stress-mediated inhibition of brain creatine kinase activity by methylmercury. Neurotoxicology 31, 454-460.

44. Aksenova M, Butterfield DA, Zhang SX, et al. (2002) Increased protein oxidation and decreased creatine kinase $\mathrm{BB}$ expression and activity after spinal cord contusion injury. J Neurotrauma 19, 491-502.

45. Gunst JJ, Langlois MR, Delanghe JR, et al. (1998) Serum creatine kinase activity is not a reliable marker for muscle damage in conditions associated with low extracellular glutathione concentration. Clin Chem 44, 939-943.

46. Khan HA, Alhomida AS, Sobki SH, et al. (2013) Serum markers of tissue damage and oxidative stress in patients with acute myocardial infarction. Biomed Res 24, 15-20.

47. Kumar Das S, Hiran KR, Mukherjee S, et al. (2007) Oxidative stress is the primary event: effects of ethanol consumption in brain. Indian J Clin Biochem 22, 99-104.

48. Mokondjimobe E, Longo-Mbenza B, Akiana J, et al. (2012) Biomarkers of oxidative stress and personalized treatment of pulmonary tuberculosis: emerging role of $\gamma$-glutamyltransferase. Adv Pharmacol Sci 2012, 465634.

49. Ismail IB, Al-Busadah KA \& El-Bahr SM (2013) Oxidative stress biomarkers and biochemical profile in broilers chicken fed zinc bacitracin and ascorbic acid under hot climate. Am J Biochem Mol Biol 3, 202-214. 